\title{
Highly Enantioselective, Base-Free Synthesis of $\alpha$-Quaternary Succinimides through Catalytic Asymmetric Allylic Alkylation
}

Tao Song, ${ }^{[a]}$ Stellios Arseniyadis* ${ }^{[a, b]}$ and Janine Cossy ${ }^{\star[a]}$

\begin{abstract}
The synthesis of diversely substituted five-membered ring succinimide derivatives is reported featuring a direct, basefree, palladium-catalyzed asymmetric allylic alkylation. The method allows a straightforward access to the desired heterocyclic scaffold bearing an all-carbon $\alpha$-quaternary stereogenic center in high yields and good to excellent enantioselectivities. To further demonstrate the synthetic utility of the method, the allylated products were further converted to various versatile chiral building blocks, including a chiral pyrrolidine and a spirocyclic derivative, using selective transformations.
\end{abstract}

Despite the number of methods reported in the literature over the past decade, the construction of $\mathrm{cyclic}^{[1]}$ and acyclic ${ }^{[2]}$ frameworks bearing a quaternary stereogenic center still remains a particularly challenging task ${ }^{[3]}$ As a matter of fact, most of these methods rely on the conjugate addition of a carbon nucleophile onto a trisubstituted pro-chiral center rather than on an electrophilic-type functionalization typically encountered in transition metal-catalyzed asymmetric allylic alkylation processes. ${ }^{[4]}$

For the past several years, we have been focused on implementing the palladium-catalyzed asymmetric allylic alkylation (Pd-AAA) to the synthesis of various chiral heterocycles including chiral isoxazolidin-5-ones, ${ }^{[5]} \beta$ lactams ${ }^{[5]}$ butenolides, ${ }^{[6]}$ furanones, ${ }^{[6]}$ butyrolactones, ${ }^{[6,7]} 4,5-$ dihydro pyrazoles ${ }^{[8]}$ and other diversely substituted $5-, 6-, 7-$, 14- and 16-membered ring $\alpha$-phosphono oxaheterocycles ${ }^{[9]}$ all bearing a quaternary stereogenic center. We logically became interested in applying this strategy to the synthesis of five membered ring succinimides. Indeed, this heterocyclic motifs is prevalent in a number of biologically active natural products such as hirsutellone $A,{ }^{[10]}$ which was isolated from the insect pathogenic fungus Hirsutella nivea BCC 2594, the haterumaimides, ${ }^{[11]}$ which are chlorinated lissoclimide-type diterpenoids isolated from an Okinawan Lissoclinum $s p$, asperparaline $A{ }^{[12]}$ which was isolated from Aspergillus japonicus $\mathrm{JV}-23$, and oxaleimide $A,{ }^{[13]}$ isolated from Penicillium oxalicum. This motif is also present in a number of pharmaceuticals such as the anticonvulsant ethosuximide ${ }^{[14]}$ and the aldose reductase inhibitor ranirestat. ${ }^{[15]}$

[a] Tao Song, Dr. S. Arseniyadis, Prof. Dr. J. Cossy Laboratoire de Chimie Organique, Institute of Chemistry, Biology and Innovation (CBI) - ESPCI Paris/CNRS (UMR8231)/PSL* Research University, 10 rue Vauquelin, 75231 Paris Cedex 05 (France) E-mail: janine.cossy@espci.fr

[b] Dr. S. Arseniyadis

Queen Mary, University of London

School of Biological and Chemical Sciences

Mile End Road, London, E1 4NS (UK)

E-mail: s.arseniyadis@qmul.ac.uk

Supporting information for this article is given via a link at the end of the document.

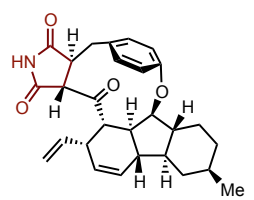

Hirsutellone A

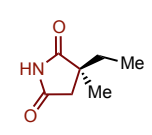

(+)-Ethosuximide

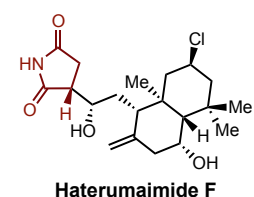

Haterumaimide $F$

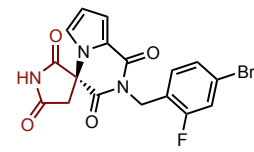

Ranirestat

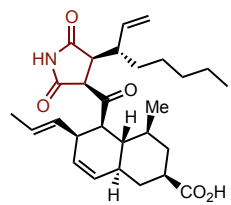

Oxaleimide A

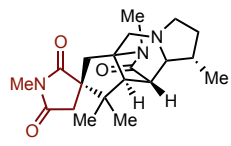

Asperparaline A
Figure 1. Typical examples of succinimide-containing natural products and pharmaceuticals.

There are a few enantioselective catalytic methods that allow a straightforward and highly enantioselective access chiral five membered ring succinimides bearing a quaternary stereogenic center at the C3-position; the most common one probably being the asymmetric Rh-catalyzed 1,4-conjugate addition of nucleophiles to 3-substituted maleimides (Figure 2, A) ${ }^{[16]}$ This method has been thoroughly investigated in the last 10 years, resulting in the development of some particularly effective chiral catalysts capable of generating the desired 3,3-disubstituted succinimide derivatives in high enantioselectivities.

Another elegant approach leading to chiral 3,3-disubstituted succinimide building blocks relies on an enantioselective organocatalytic addition of an $\alpha$-ketoamide onto an $\alpha, \beta$-unsaturated aldehyde (Figure 2, B). ${ }^{[17]}$ This formal $[3+2]$
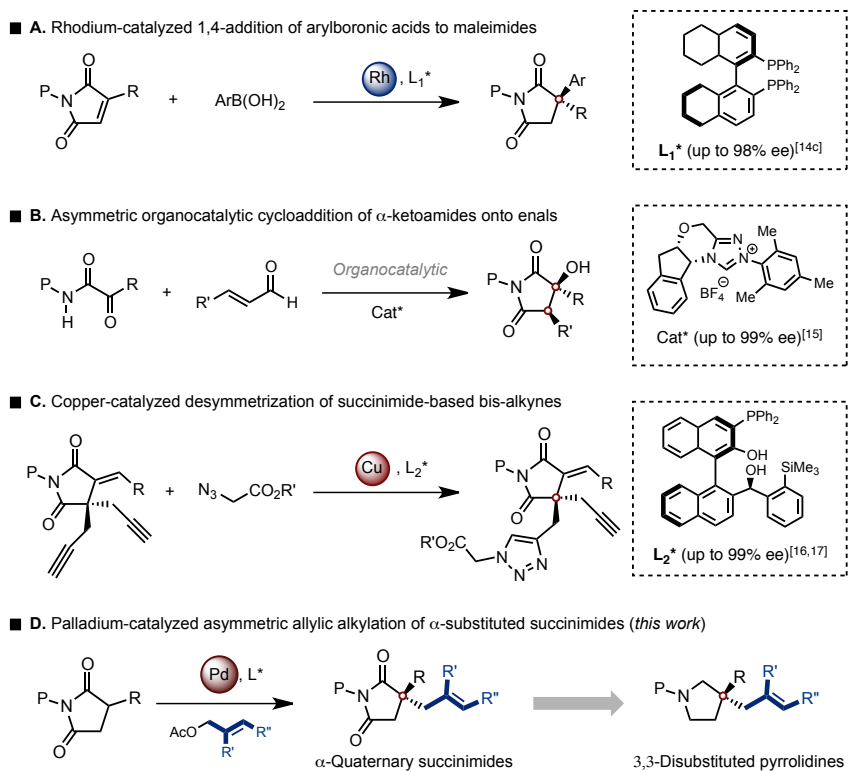

Figure 2. Selected strategies for the asymmetric synthesis of chiral succinimide derivatives. 


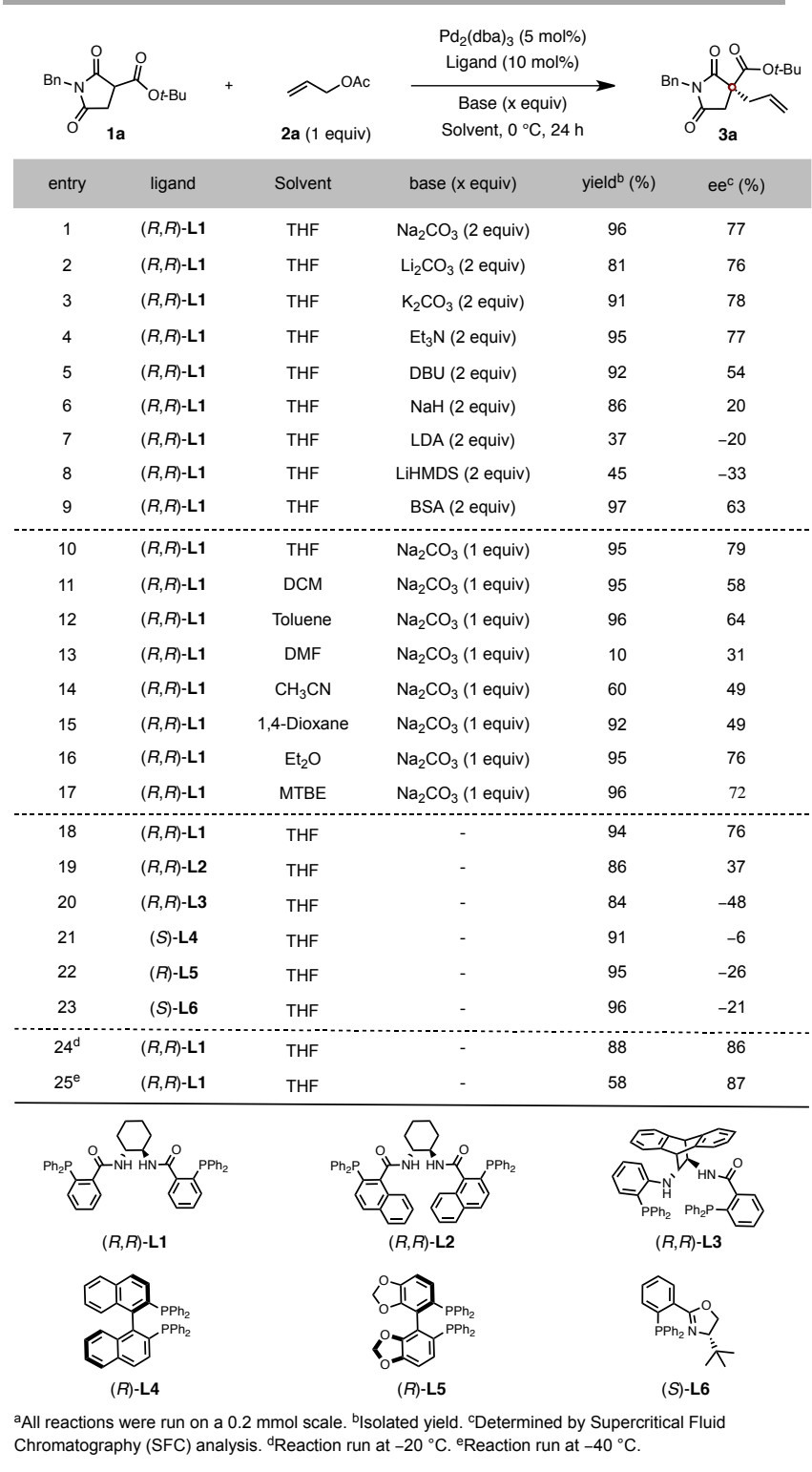

cycloaddition relies on the use of chiral NHCs to catalyze the formation of the corresponding chiral azolium enolate intermediates and thus promote sufficient facial discrimination to afford the corresponding chiral succinimide with excellent levels of enantioselectivity.

Finally, another interesting strategy to prepare these chiral five-membered ring succinimide derivatives bearing an all-carbon quaternary center is through a copper-catalyzed desymmetrization of a bis-alkyne-based $\alpha$-alkylidene succinimide precursor (Figure 2, C).${ }^{[18]}$ A number of effective chiral ligands ${ }^{[19]}$ were reported to afford the corresponding $\alpha$-quaternary succinimide derivatives with ees up to $99 \%$, independently of the aromatic substitution on the alkylidene moiety.

For our part, we opted for an electrophilic-type functionalization and envisioned a direct, base-free, Pd-AAA type reaction applied to 3-substituted succinimide derivatives (Figure 2, D). Indeed, if successful, this approach would allow a straightforward and potentially highly enantioselective access to enantioenriched succinimides bearing an all carbon $\alpha$-quaternary stereogenic center.

We initiated our study using the racemic $N$-benzyl-3-tertbutylcarboxylate derivative $1 \mathrm{a}$ as a model substrate. The latter was prepared in two steps and $57 \%$ overall yield starting from commercially available succinimide. With compound 1a in hand, we initiated our study by probing the effect of the experimental conditions on both the efficiency and the selectivity of the reaction; these results are depicted in Table 1.

The first parameter to be evaluated was the base. The reactions were thus run in $\mathrm{THF}$ at $0^{\circ} \mathrm{C}$ using allyl acetate (1.0 equiv.), the selected base (2.0 equiv.), $\mathrm{Pd}_{2}(\mathrm{dba})_{3}$ (5.0 mol\%) and Trost's ligand, $(R, R)$-L1 (10 mol\%), which had previously given the best selectivities in the Pd-AAA of cyclic dienol carbonates. ${ }^{[6]}$ As a general trend, all the reactions readily afforded the corresponding allylated product in moderate to good enantioselectivities (Table 1, entries 1-9). Interestingly, both inorganic and organic weak bases led to similar levels of reactivity and selectivity as exemplified by the ees obtained with $\mathrm{Na}_{2} \mathrm{CO}_{3}(77 \%$ ee) (Table 1, entry 1$), \mathrm{Li}_{2} \mathrm{CO}_{3}$ (76\% ee) (Table 1, entry 2 ), $\mathrm{K}_{2} \mathrm{CO}_{3}$ (78\% ee) (Table 1 , entry 3$)$ and $\mathrm{Et}_{3} \mathrm{~N}(77 \%$ ee) (Table 1 , entry 4$)$. In sharp contrast, strong bases such as DBU $(54 \%$ ee) (Table 1, entry $5)$, $\mathrm{NaH}(20 \%$ ee) (Table 1, entry 6$)$, LDA (20\% ee) (Table 1 , entry 7 ) and LiHMDS (33\% ee) (Table 1, entry 8 ) had a detrimental effect on the enantioselectivity. Moreover, a reversed selectivity was observed when using LDA and LiHMDS, which can probably be accounted for by the structural difference of the corresponding lithium enolates. ${ }^{[20]}$ Ultimately, the use of 1.0 equiv of $\mathrm{Na}_{2} \mathrm{CO}_{3}$ was sufficient to reach a similar outcome $(79 \%$ ee) (Table 1 , entry 10$)$.

With these results in hand, we next evaluated the influence of the solvent. Once again, all the reactions afforded the corresponding allylated product in good yields and moderate to good enantioselectivities independently of the nature of the solvent (Table 1, entries 10-17); THF remaining the best among all the ones that were tested.

Considering the acidity of the $\alpha$-proton and the basicity of the acetate released during the process, we wondered whether the reaction could be run in the absence of added base under otherwise identical conditions. To our delight, we were able to isolate the corresponding $\alpha$-allylated product in almost quantitative yield and up to $76 \%$ ee (Table 1 , entry 18 ). Based on this result, we next set out to evaluate the influence of the chiral ligand. As a general trend, all the reactions proceeded efficiently, independently of the ligand used. However the chiral palladium catalysts derived from C2-symmetric bis-phosphines, such as L1, L2 and L3, displayed higher levels of selectivity (Table 1, entries 18-20) than the axially dissymmetric $\mathrm{C}_{2}$ chiral diphosphines, BINAP (L4, 6\% ee) (Table 1, entry 21) and SEGPHOS (L5, 26\% ee) (Table 1, entry 22), and the mixed $\mathrm{P} / \mathrm{N}$-type ligands such as the phosphine-oxazoline (PHOX) ligand L6 $(21 \%$ ee $)$ (Table 1, entry 23). Ultimately, the use of the $(R, R)-\mathrm{DACH}-$ phenyl ligand(L1, $10 \mathrm{~mol} \%)$ in conjunction with $\mathrm{Pd}_{2}(\mathrm{dba})_{3}$ (10 mol\%) led to the highest level of selectivity, affording the $\alpha, \alpha$-disubstituted succinimide $3 a$ in $94 \%$ yield and $76 \%$ ee (Table 1, entry 18). This result could be improved by performing the reaction at $-20{ }^{\circ} \mathrm{C}$ without altering the yield (86\% ee) (Table 1 , entry 24$)$.

To optimize this Pd-AAA reaction further, we also evaluated the influence of the allyl donor and found allyl acetate $(88 \%$ yield, $86 \%$ ee) to be superior to allyl benzoate ( $58 \%$ yield, $86 \%$ ee) and allyl methyl carbonate $(96 \%$ yield, $63 \%$ ee), while reducing the palladium loading from $10 \mathrm{~mol} \%$ ( $77 \%$ yield, $92 \%$ ee) to $2 \mathrm{~mol} \%$ ( $41 \%$ yield, $93 \%$ ee) afforded roughly the same selectivity but drastically reduced the yield 
Table 2. Investigation of the reaction scope (Part I). ${ }^{a}$

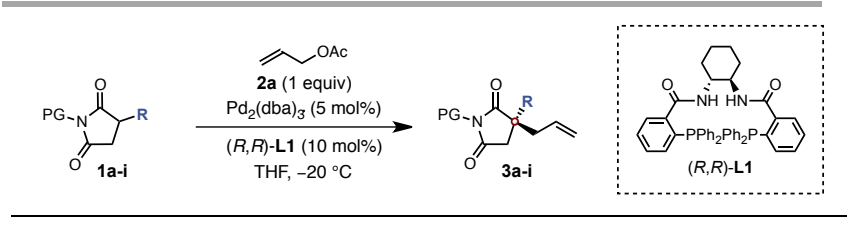

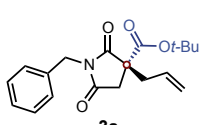

$\left(88 \%,{ }^{\text {, }}\right.$ ee $\left.=86 \%^{c}\right)$

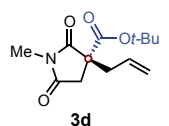

$\left(83 \%,{ }^{\text {, }}\right.$ ee $\left.=87 \%{ }^{c}\right)$

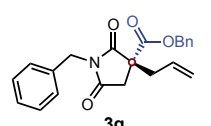

$\left(96 \%\right.$, , $\left.{ }^{3 g}=11 \%{ }^{c}\right)$

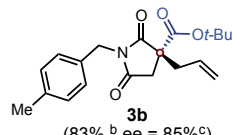

$\left(83 \%,{ }^{\text {b ee }}=85 \%{ }^{\mathrm{c}}\right)$



$\left(96 \%\right.$, , ${ }^{3 e}$ ee $\left.=19 \%{ }^{c}\right)$

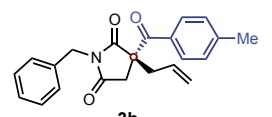

$\left(88 \%,{ }^{\text {b }}\right.$ ee $\left.^{\text {h }}=48 \%{ }^{c}\right)$
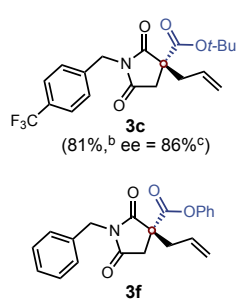

$\left(95 \%,{ }^{\text {b }}\right.$ ee $\left.=44 \%{ }^{\text {c }}\right)$

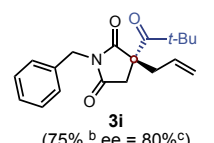

aAll reactions were run on a $0.2 \mathrm{mmol}$. blsolated yield. CDetermined by Supercritical Fluid Chromatography analysis.

even after a prolonged reaction time (up to $65 \mathrm{~h}$ ) (not shown in the Table; see Supporting Information for more details).

With an optimal asymmetric reaction protocol in hand $\left[\mathrm{Pd}_{2}(\mathrm{dba})_{3}(5 \mathrm{~mol} \%),(R, R)-\mathrm{L} 1(10 \mathrm{~mol} \%), \mathrm{THF},-20^{\circ} \mathrm{C}\right]$, we next examined the substrate scope by applying these conditions to various succinimide derivatives $1 \mathrm{a}-\mathrm{i}$. The results are summarized in Table 2. The first structural element that was evaluated was the nature of the protecting group on the nitrogen atom. Preliminary data showed that both electronrich and electron-poor benzyl protecting groups led to similar levels of selectivity (3a-c, $\approx 85 \%$ ee). Interestingly, replacing the benzyl protecting group by a methyl did not alter the selectivity (3d, $87 \%$ ee), however we decided to remain with the benzyl protecting group for the rest of the study. Replacing the tert-butyl ester at the C3-position by a methyl ester (3e, 19\% ee), a phenyl ester (3f, 44\% ee), a benzyl ester $(\mathbf{3 g}, 11 \%$ ee) or a para-tolyl ketone $(3 \mathbf{h}, 48 \%$ ee) terribly decreased the selectivity, while the introduction of the more hindered tert-butyl ketone ( $\mathbf{3 i}, 80 \%$ ee) brought the selectivity back to a descent level.

In an effort to broaden the scope of the reaction further, a variety of 2-substituted allyl acetates 2a-f were engaged in the allylation process. As the reactions appeared to be more sluggish, we decided to run them at room temperature instead. The results are depicted in Table 3. Interestingly, replacing the hydrogen atom at the C2-position by a methyl (4a, $89 \%$ ee), a trimethylsilyl (4b, $87 \%$ ee) or a chlorine atom (4c, $85 \%$ ee) afforded the corresponding allylated products in roughly the same selectivity, albeit in slightly lower yields. Unfortunately, replacing the hydrogen atom by a phenyl (4d, $47 \%$ ee) or a methyl ester $(4 \mathrm{e}, 55 \%$ ee) led to much lower enantioselectivities.

Various 3-substituted allyl acetates $\mathbf{2 g}-\mathbf{v}$ were also evaluated, notably diversely substituted cinnamyl acetate, which all gave good to excellent enantioselectivities as exemplified by the ees obtained for $\mathbf{5 a - j}$ ranging from $76 \%$ to $96 \%$ (Table 4). Hence, ortho-substituted cinnamyl acetates such as the ones used to prepare succinimides $\mathbf{5 b}$ and $\mathbf{5 e}$ gave slightly lower ees than the ones used to access the meta- (5c and 5f) and para-analogues (5d and $\mathbf{5 g}-\mathbf{j}$ ) independently of the steric and electronic features of the
Table 3. Investigation of the reaction scope (Part II). ${ }^{a}$

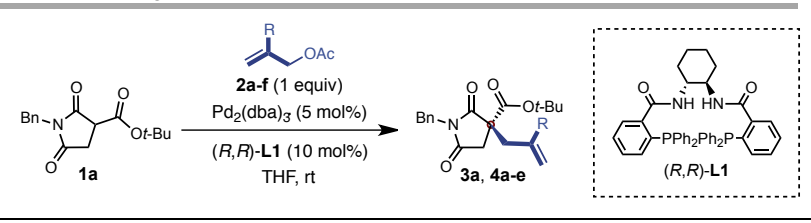



$\left(88 \%,{ }^{3}\right.$ ee $\left.=86 \%{ }^{d}\right)$

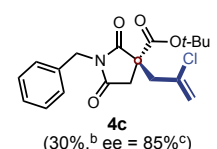

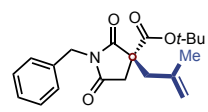

$\left(54 \%,{ }^{\mathrm{b}} \mathrm{ee}=89 \%{ }^{\mathrm{c}}\right)$

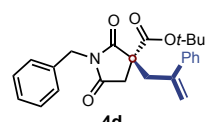

$\left(55 \%,{ }^{\mathrm{b}}\right.$ ee $\left.=47 \%{ }^{\mathrm{c}}\right)$



$\left(61 \%,{ }^{\mathrm{b}} \mathrm{ee}=87 \%^{\mathrm{c}}\right)$

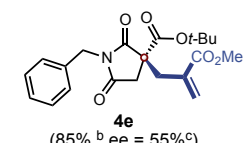

aAll reactions were run on a $0.2 \mathrm{mmol}$. blsolated yield. 'Determined by Supercritical Fluid Chromatography (SFC) analysis. dReaction performed at $-20^{\circ} \mathrm{C}$.

substituents. As a general trend, all the para-substituted cinnamyl acetates, such as the para-methyl (5d, 96\% ee), para-bromo (5g, 89\% ee), para-methoxy (5i, 94\% ee) and para-phenyl $(\mathbf{5 j}, 92 \%$ ee), afforded the corresponding $\alpha$-allylated products with higher ees. In addition, cinnamyl acetates bearing an electron-withdrawing group such as a trifluoromethyl $\mathbf{( 5 \mathbf { h } , 7 7 \%}$ ee) clearly induced lower enantioselectivities than the ones featuring an electrondonating substituent such as a methoxy (5i, 94\% ee). Most importantly, 3-substituted allyl acetates bearing a heterocyclic substituent, such as a thiophene $(\mathbf{5 I}, 95 \%$ ee) or a furan $\mathbf{( 5 m}$, $95 \%$ ee), or an aliphatic substituent such as an $n$-propyl (5o, $90 \%$ ee), all afforded fantastic levels of enantioselectivity. Interestingly, diallyl acetate only afforded the mono allylated product $5 p$ in $79 \%$ ee albeit in a low $26 \%$ yield.

Finally, six-membered ring succinimides could also undergo allylation under our optimized conditions affording the corresponding allylated product $\mathbf{5 q}$ with up to $73 \%$ ee, however the selectivity dropped as soon as we replaced allyl acetate by cinnamyl acetate $\left(5 r, 44 \%\right.$ ee). ${ }^{[21]}$

The absolute configuration of the newly formed quaternary center was later confirmed by single crystal X-Ray analysis of compound $\mathbf{5 g}$ (see structure in Table 4). As a matter of fact, this stereoselectivity could have also been predicted using the model proposed by Trost et al. ${ }^{[22]}$ where the enolate approaches the $\pi$-allyl palladium- $(R, R)-\mathbf{L} \mathbf{1}$ complex by its $R e$ face to avoid any disfavored steric interaction between the "wall" of the ligand and the amide moiety of the substrate (Figure 3).

To further demonstrate the synthetic utility of the method, we converted the allylated products $\mathbf{3 a}$ and $\mathbf{5 a}$ to various useful building blocks through simple synthetic procedures (Scheme 1). Compound $3 \mathbf{a}$ was thus subjected to standard iodolactonization conditions $\left(\mathrm{I}_{2}, \mathrm{CH}_{2} \mathrm{Cl}_{2}, \mathrm{rt}\right)$. The corresponding spirocyclic derivatives $\mathbf{6 a}$ and $\mathbf{6 b}$ where obtained as a mixture of two diastereoisomers (de $=55 \%$ ) with no erosion of the stereochemical integrity of the starting material. The same compound $3 \mathbf{a}$ was also subjected to ozonolysis $\left(\mathrm{O}_{3}, \mathrm{CH}_{2} \mathrm{Cl}_{2},-78{ }^{\circ} \mathrm{C}\right.$, then $\mathrm{PPh}_{3}$, rt), hydrogenation $\left(\mathrm{H}_{2}, \mathrm{Pd} / \mathrm{C}\right.$, EtOAc, rt) and cross-metathesis conditions to afford aldehyde $\mathbf{7}$, the aliphatic derivative 8 and the disubstituted olefin 9 in $85 \%, 98 \%$ and $55 \%$ yield respectively. Finally, compound $\mathbf{5 a}$ was converted to the corresponding pyrrolidine 10 bearing a quaternary all-carbon stereogenic 
Table 4. Investigation of the reaction scope (Part III). ${ }^{a}$

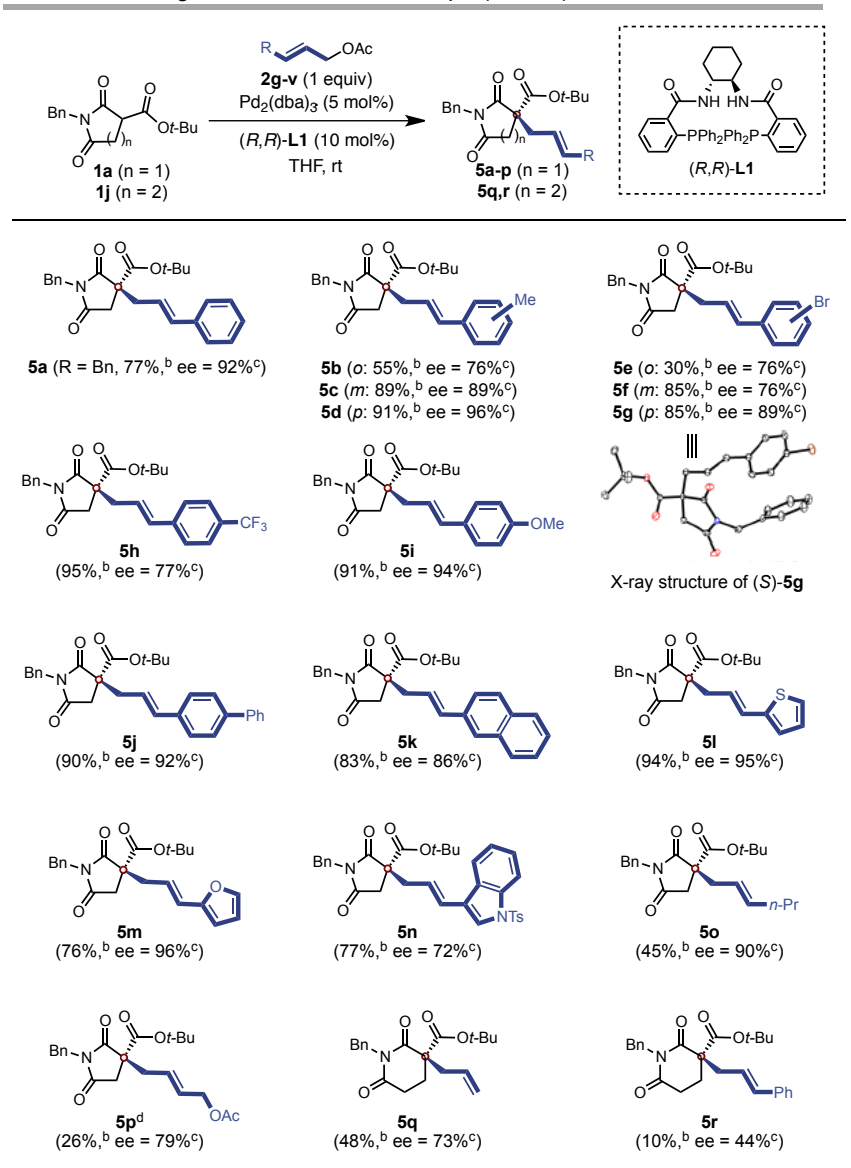

aAll reactions were run on a $0.2 \mathrm{mmol}$. blsolated yield. ${ }^{\mathrm{c}}$ Determined by Supercritical Fluid Chromatography (SFC) analysis. ${ }^{d}$ Reaction performed at $-20^{\circ} \mathrm{C}$.
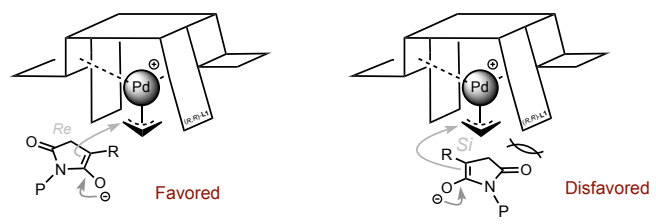

Figure 3. Proposed stereochemical pathway.

center in $70 \%$ yield through a Red-Al-mediated reduction of the two carbonyl moieties.

In summary, we have developed an efficient, base free and highly enantioselective Pd-AAA process to access chiral succinimide derivatives bearing an all-carbon $\alpha$-quaternary stereogenic center. $(R, R)-\mathrm{DACH}-\mathrm{Phenyl}$ Trost ligand $\mathbf{L} 1$ was found to be the most effective ligand for this reaction, allowing to generate the desired products in high yields and up to $96 \%$ ee. The absolute configuration of the newly generated stereogenic center was confirmed by single crystal X-Ray analysis. Most importantly, the method is highly versatile as it tolerates the use of a wide variety of substituted allyl acetates. In addition, the resulting chiral succinimide derivatives can be easily converted to a number of useful building blocks through simple synthetic derivatizations.



Scheme 1. Derivatization of compounds $3 \mathbf{a}$ and $\mathbf{5 a}$

\section{Experimental Section}

General procedure for the Pd-AAA with allyl acetate: To a solution of $\mathrm{Pd}_{2}(\mathrm{dba})_{3}(0.01 \mathrm{mmol}, 0.05$ equiv) in THF (1 mL) at $\mathrm{rt}$ was added $(R, R)$-L1 $(0.02 \mathrm{mmol}, 0.1$ equiv) and the mixture was stirred for $30 \mathrm{~min}$. This solution was then cooled to $0{ }^{\circ} \mathrm{C}$ and transferred via cannula to a flask containing a cooled solution $\left(0^{\circ} \mathrm{C}\right)$ of 3 -substituted succinimide ( $0.20 \mathrm{mmol}, 1.0$ equiv) in THF (1 mL). Once the addition was completed, allyl acetate $(0.20 \mathrm{mmol}, 1.0$ equiv) was added and the reaction mixture was stirred at the same temperature until complete consumption of the starting material (reaction monitored by TLC). The reaction mixture was eventually filtered through a plug of Celite ${ }^{\odot}$ and concentrated under reduced pressure to afford a crude residue, which was purified by flash column chromatography over silica gel.

\section{Acknowledgements}

Financial support from the CSC foundation (China Scholarship Council) is gratefully acknowledged.

Keywords: asymmetric catalysis - allylic alkylation • succinimides $\cdot$ pyrrolidines $\cdot$ palladium $\cdot$ enantioselectivity

[1] (a) Y. Liu, S.-J. Han, W.-B. Liu, B. M. Stoltz, Acc. Chem Res. 2015, 48, 740-751; (b) G. Eppe, D. Didier, I. Marek, Chem. Rev. 2015, 115, 9175-9206; (c) K. W. Quasdorf, L. E. Overman, Nature 2014, 516, 181-191; (d) I. Marek, Y. Minko, M. Pasco, T. Mejuch, N. Gilboa, H. Chechik, J. P. Das, J. Am. Chem. Soc. 2014, 136, 2682-2694; (e) A. Y. Hong, B. M. Stoltz, Eur. J. Org. Chem. 2013, 14, 2745-2759; (f) B. M. Trost, C. Jiang, Synthesis 2006, 369-396; (g) J. Christoffers, A. Baro, Adv. Synth. Catal. 2005, 347, 14731482; (h) E. A. Peterson, L. E. Overman, Proc. Natl. Acad. Sci. U. S. A. 2004, 101, 11943-11948; (i) J. Christoffers, A. Mann, Angew. Chem. Int. Ed. 2001, 40, 4591-4597; (j) E. J. Corey, A. Guzman-Perez, Angew. Chem. Int. Ed. 1998, 37, 388-401.

[2] (a) J. Feng, M. Holmes, M. J. Krische, Chem. Rev. 2017, 117, 12564-12580; (b) S. Singh, J. Bruffaerts, A. Vasseur, I. Marek, Nat. Commun. 2017, 8, 14200; (c) G. Pupo, R. Properzi, B. List, Angew. Chem. Int. Ed. 2016, 55, 60996102; (d) S. R. Roy, D. Didier, A. Kleiner, I. Marek, Chem. Sci. 2016, 7, 5989-5994; (e) F.-G. Zhang, G. Eppe, I. Marek, Angew. Chem. Int. Ed. 2016, 55, 714-718; (f) B. M. Trost, E. J. Donckele, D. A. Thaisrivongs, M. Osipov, J. T. Masters, J. 
Am. Chem. Soc. 2015, 137, 2776-2784; (g) P.-O. Delaye, D. Didier, I. Marek, Angew. Chem. Int. Ed. 2013, 52, 53335337.

[3] X.-P. Zeng, Z.-Y. Cao, Y.-H. Wang, F. Zhou, J. Zhou, Chem. Rev. 2016, 116, 7330-7396.

[4] (a) B. M. Trost, D. L. Van Vranken, Chem. Rev. 1996, 96, 395-422; (b) G. J. Helmchen, Organomet. Chem. 1999, 576, 203-214; (c) B. M. Trost, M. L. Crawley, Chem. Rev. 2003, 103, 2921-2944; (d) H. Miyabe, Y. Takemoto, Synlett 2005, 1641-1655; (e) J. T. Mohr, B. M. Stoltz, Chem. Asian J. 2007, 2, 1476-1491; (f) Z. Lu, S. Ma, Angew. Chem. Int. Ed. 2008, 47, 258-297; (g) J. D. Weaver, A. Recio, A. J. Grenning, J. A. Tunge, Chem. Rev. 2011, 111, 1846-1913; (h) S. Oliver, P. A. Evans, Synthesis 2013, 45, 3179-3198; (i) N. A. Butt, W. Zhang, Chem. Soc. Rev. 2015, 44, 7929-7967.

[5] M. N. De Oliveira, S. Arseniyadis, J. Cossy, Chem. Eur. J. 2018, (DOI: 10.1002/chem.201800641).

[6] (a) J. Fournier, S. Arseniyadis, J. Cossy, Angew. Chem. Int. Ed. 2012, 51, 7562-7566; (b) J. Fournier, O. Lozano, C. Menozzi, S. Arseniyadis, J. Cossy, Angew. Chem. Int. Ed. 2013, 52, 1257-1261; (c) S. Arseniyadis, J. Fournier, S. Thangavelu, O. Lozano, S. Prevost, A. Archambeau, C. Menozzi, J. Cossy, Synlett. 2013, 2350-2364.

[7] M. N. De Oliveira, J. Fournier, S. Arseniyadis, J. Cossy, Org, Lett. 2017, 19, 14-17.

[8] H. Elhachemia, M. Cattoen, M. Cordier, J. Cossy, S. Arseniyadis, H. Ilitki, L. El Kaïm, Chem. Commun. 2016, 52, 14490-14493.

[9] M. Dolé Kerim, M. Cattoen, N. Fincias, A. Dos Santos, S. Arseniyadis, L. El Kaïm, Adv. Synth. Catal. 2018 (DOI: 10.1002/adsc.201701150).

[10] M. Isaka, N. Rugseree, P. Maithip, P. Kongsaeree, S. Prabpai, Y. Thebtaranonth, Tetrahedron 2005, 61, 5577-5583.

[11] M. J. Uddin, S. Kokubo, K. Ueda, K. Suenaga, D. Uemura, J. Nat. Prod. 2001, 64, 1169-1173.

[12] H. Hayashi, Y. Nishimoto, H. Nozaki, Tetrahedron Lett. 1997, 38, 5655-5658.

[13] M. Sato, J. E. Dander, C. Sato, Y.-S. Hung, S.-S. Gao, M.-C. Tang, L. Hang, J. M. Winter, N. K. Garg, K. Watanabe, Y. Tang, J. Am. Chem. Soc. 2017, 139, 53175320 .

[14] (a) D. A. Coulter, J. R. Huguenard, D. A. Prince, Br. J. Pharmacol. 1990, 100, 800-806; (b) S. M. Todorovic, C. J. Lingle, J. Neurophysiol. 1998, 79, 240-252; (c) J. C. Gomora, A. N. Daud, M. Weiergräber, E. Perez-Reyes, Mol. Pharmacol. 2001, 60, 1121-1132.

[15] V. Bril, T. Hirose, S. Tomioka, R. Buchanan, Diabetes Care 2009, 32, 1256-1260.

[16] (a) R. Shintani, K. Ueyama, I. Yamada, T. Hayashi, Org. Lett. 2004, 6, 3425-3427; (b) R. Shintani, W.-L. Duan, T. Nagano, A. Okada, T. Hayashi, Angew. Chem. Int. Ed. 2005, 44, 46114614; (c) R. Shintani, W. L. Duan, T. Hayashi, J. Am. Chem. Soc. 2006, 128, 5628-5629; (d) E. Piras, F. Läng, H. Rüegger, D. Stein, M. Wörle, H. Grützmacher, Chem. Eur. J. 2006, 12, 5849-5858; (e) W.-L. Duan, H. Iwamura, R. Shintani, T. Hayashi, J. Am. Chem. Soc. 2007, 129, 2130-2138; (k) Y. Luo, A. J. Carnell, Angew. Chem. Int. Ed. 2010, 49, 2750-2754; (f) T. Thaler, L.-N. Guo, A. K. Steib, M. Raducan, K. Karaghiosoff, P. Mayer, P. Knochel, Org. Lett. 2011, 13, 3182-3185; (g) W.-L. Duan, Y. Imazaki, R. Shintani, T. Hayashi, Tetrahedron 2007, 63, 8529-8536; (h) F. Berhal, Z. Wu, J.-P. Genet, T. Ayad, V. Ratovelomanana-Vidal, J. Org. Chem. 2011, 76, 63206326; (i) F. Le Boucher d'Herouville, A. Millet, M. Scalone, V. Michelet, J. Org. Chem. 2011, 76, 6925-6930; (j) T. Korenaga, A. Ko, K. Shimada, J. Org. Chem. 2013, 78, 9975-9980.

[17] L. Wang, Q. Ni, M. Blümel, T. Shu, G. Raabe, D. Enders, Chem. Eur. J. 2015, 21, 8033-8037.

[18] T. Song, L. Li, W. Zhou, Z. J. Zheng, Y. Deng, Z. Xu, L.-W. $\mathrm{Xu}$, Chem. Eur. J., 2015, 21, 554-558.
[19] M. Y. Chen, T. Song, Z.-J. Zheng, Z. Xu, Y.-M. Cui, L.-W. $\mathrm{Xu}, R S C A d v$., 2016, 6, 58698-58708.

[20] B. M. Trost, J. Xu, T. Schmidt, J. Am. Chem. Soc. 2009, 131, 18343-18357.

[21] A closely related decarboxylative Pd-AAA strategy was reported by Stoltz et al. for the synthesis of six-membered ring succinimides, see: (a) N. B. Bennett, D. C. Duquette, J. Kim, W.-B. Liu, A. N. Marziale, D. C. Behenna, S. C. Virgil, B. M. Stoltz, Chem. Eur. J. 2013, 19, 4414-4418; (b) D. C. Behenna, Y. Liu, T. Yurino, J. Kim, D. E. White, S. C. Virgil, B. M. Stoltz, Nature Chem. 2012, 4, 130-133.

[22] B. M. Trost, Org. Process. Res. Dev. 2012, 16, 185-194. 